\title{
Optimization of Sour Cherry Juice Spray Drying as Affected by Carrier Material and Temperature
}

\author{
Ivona Elez Garofulićc ${ }^{1 *}$, Zoran Zorić ${ }^{2}$, Sandra Pedisić ${ }^{2}$ and Verica Dragović-Uzelac ${ }^{1}$ \\ ${ }^{1}$ Faculty of Food Technology and Biotechnology, University of Zagreb, Pierottijeva 6, \\ HR- 10000 Zagreb, Croatia \\ ${ }^{2}$ Faculty of Food Technology and Biotechnology, Centre Zadar, Petra Kasandrića 6, \\ HR- 23000 Zadar, Croatia \\ Received: January 8, 2016 \\ Accepted: June 10, 2016
}

\begin{abstract}
Summary
Response surface methodology was applied for optimization of the sour cherry Marasca juice spray drying process with 20,30 and $40 \%$ of carriers maltodextrin with dextrose equivalent (DE) value of 4-7 and 13-17 and gum arabic, at three drying temperatures: 150, 175 and $200{ }^{\circ} \mathrm{C}$. Increase in carrier mass per volume ratio resulted in lower moisture content and powder hygroscopicity, higher bulk density, solubility and product yield. Higher temperatures decreased the moisture content and bulk density of powders. Temperature of $200{ }^{\circ} \mathrm{C}$ and $27 \%$ of maltodextrin with $4-7 \mathrm{DE}$ were found to be the most suitable for production of sour cherry Marasca powder.
\end{abstract}

Key words: sour cherry juice, spray drying, optimization, physicochemical properties

\section{Introduction}

Economic and industrial development influenced changes in consumer trends, focusing on the consumption of fresh fruits and vegetables as the healthy, nutritive and biologically valuable food, rich in biologically active components. However, fruits and vegetables are highly perishable products, so in order to answer to market demands and ensure their longer period of availability, industry offers different preservation and processing techniques. The main problem regarding the storage of fruit products is high water content, which makes them susceptible to elevated enzymatic activity and microbial growth, leading to quality degradation and deterioration. The prolongation of fruit product shelf life and stability can be achieved by drying as one of the most commonly used preservation techniques for reduction of the water content of food, and subsequently for reduction of microbial growth as well as enzymatic activity. Furthermore, drying reduces the mass and volume of food products resulting in lower storage and transportation costs and making the product easier to handle (1). Numerous drying methods have been developed aiming to increase productivity, processing control as well as the quality of the final product. Spray drying is a widely spread technique for drying of liquid products, such as fruit juices, into powder form. However, during drying of fruit juices, stickiness on the drier wall, wet, plastic appearance, agglomeration and clumping occur, resulting in operational problems and increased losses (2). Low glass transition temperature of sugars, which make about $90 \%$ of juice dry matter, is the main cause of the stickiness (3). Common approaches for a solution to this problem involve modifying the sticky characteristics of the material most frequently through the addition of carrier agents and controlling the inlet and outlet temperature of the dryer (4). Advantages of this method mainly include short drying period because of a large heat transfer surface, low product surface temperature, no direct contact of food with heated metal surface, stability and high quality of the final product. As fruit powders have a variety of potential uses in food industry, as semi-products or final products 
with high nutritive and functional benefits, optimizing the spray drying process is a worthwhile step.

Sour cherry Marasca (Prunus cerasus var. Marasca) is a cultivar characterized by high content of dry matter (21.0-27.3 \%) (5), biologically active compounds (polyphenols, melatonin and vitamin C), dark red colour and intense sweet-sour aroma (5-8). Although it is rarely consumed fresh, the possibilities for processing are numerous: jams, juices and concentrated juices, frozen and dried products, among which fruit powders are recognized. Because of its intense colour, flavour and high dry matter content, sour cherry Marasca juice is a great material for production of spray-dried fruit powders. However, Marasca juice is a demanding material for spray drying and preservation of its natural attributes such as colour, aroma and flavour. Moreover, the characteristics of spray-dried sugar-rich juices, especially the hygroscopicity and thermoplastic behaviour, put additional requirements on the selection of processing parameters. Sour cherry Marasca juice has high content of low-molecular-mass sugars such as glucose and fructose, which cause stickiness and caking during the spray drying and therefore disable the production of free-flowing dry powder (9). In practice, this problem is solved by the addition of carrier materials, such as polymers and gums, which prevent the stickiness, and by the careful selection of processing parameters such as drying temperature, air flow and material flow (10). Most frequently used carrier materials are maltodextrins (MD) of different dextrose equivalents (DE). Vardin and Yasar (11) optimized the spray drying process of pomegranate juice with $40 \%$ dry matter using MDs of 7 and $18 \mathrm{DE}$ added in ratios of juice dry matter and MD of $1: 1,3: 4$ and $1: 2$, at temperatures of 110,140 and $170{ }^{\circ} \mathrm{C}$. At the ratio $1: 2$, product yield was over $72 \%$ at temperatures of $110-140{ }^{\circ} \mathrm{C}$ and about $67 \%$ at $170{ }^{\circ} \mathrm{C}$. At the ratio $1: 1$, yield was significantly lower, $25-51 \%$. Dextrose equivalent was also found to be significant, as maltodextrin with lower dextrose equivalent gave higher yields at higher mass per volume ratios and lower temperatures. Moisture content of the powders decreased with the increased inlet and outlet air temperature, while solubility increased. The hygroscopicity of spray-dried powders increased with increased DE value of MD and slightly decreased with increased inlet air temperature. Solval et al. (12) researched the effect of temperature $\left(170,180\right.$ and $\left.190{ }^{\circ} \mathrm{C}\right)$ on the properties of melon juice produced with MD 9-13 DE added in the ratio of juice and MD of 9:1. The increase in temperature caused the reduction of moisture content from 5.39 to $3.81 \%$. According to these literature reports, it can be concluded that spray drying parameters as well as the carrier addition highly depend on the material that is to be dried and therefore should be carefully optimized. Because of the differences between Marasca and other sour cherry cultivars, especially regarding the significantly higher dry matter content, sour cherry Marasca is a challenging material for spray drying. Therefore, the aim of this research is to optimize the spray drying process of sour cherry Marasca juice in terms of carrier material selection, its concentration and drying temperature and to determine the influence of the above-mentioned parameters on physicochemical properties of sour cherry Marasca fruit powders.

\section{Materials and Methods}

\section{Material}

Sour cherry juice $\left(15^{\circ}\right.$ Brix $)$ used for experiment was obtained from Maraska d.d. factory (Zadar, Croatia). Industrial juice production included following steps: fruit washing, heating at $45-50{ }^{\circ} \mathrm{C}$, one-hour treatment with 20-40 mL/t of pectolytic and amylolytic enzymes (Endozym Pectofruit PR, AEB Group, Brescia, Italy), pressing with Bucher press (Bucher Vaslin SA, Chalonnes sur Loire, France), 2-minute pasteurisation at $85{ }^{\circ} \mathrm{C}$, cooling to $50{ }^{\circ} \mathrm{C}$, two-hour treatment with $2-3 \mathrm{~g} / \mathrm{hL}$ of pectolytic enzyme (Endozym Pectofruit), precipitation and vacuum and plate filtration. The juice was stored in dark glass bottles at $4{ }^{\circ} \mathrm{C}$ until analysis.

Three different carriers were used for production of spray-dried juice, namely maltodextrin with dextrose equivalent of 4-7 (MD 4-7 DE), maltodextrin with dextrose equivalent of 13-17 (MD 13-17 DE) and gum arabic (GA). All carriers were obtained from Sigma-Aldrich (Taufkirchen, Germany).

\section{Spray drying process}

Sour cherry Marasca juice powders were produced on a laboratory scale spray dryer SD 06 (Labplant, North Yorkshire, UK). During the process the following parameters were kept at constant level: air flow $3.5 \mathrm{~m} / \mathrm{s}$, feed flow $485 \mathrm{~mL} / \mathrm{h}$ and deblocking speed at medium level. Spray drying process was carried out according to the experimental design as follows: three different carriers (MD 4-7 DE, MD 13-17 DE and GA) were added at 20, 30 and $40 \%$ (by mass per volume) to the $100 \mathrm{~mL}$ of sour cherry Marasca juice ( $15^{\circ}$ Brix). The slurry was stirred and preheated to $50{ }^{\circ} \mathrm{C}$ on a magnetic stirrer (HSC Ceramic Hot Top-Plate Stirrer, VELP Scientifica Srl, Usmate Velate (MB), Italy) for $10 \mathrm{~min}$ in order to achieve homogeneous dispersion of carrier material in juice. The slurries were spray dried at three different inlet temperatures, 150, 175 and $200{ }^{\circ} \mathrm{C}$. The corresponding outlet temperatures were 78-80, 87-90 and 99-102 ${ }^{\circ} \mathrm{C}$, respectively. All powders were produced in duplicate and stored in dark plastic containers in a desiccator at $20^{\circ} \mathrm{C}$ until analysis.

\section{Analytical methods}

\section{Product yield}

Product yield was calculated as the ratio of the dry matter content of the collected powder to the dry matter content of the slurry according to the following equation:

$$
\text { Product yield }=\frac{m_{\mathrm{p}}}{m_{\mathrm{d}}+m_{\mathrm{c}}} \cdot 100
$$

where $m_{\mathrm{p}}$ is the mass $(\mathrm{g})$ of produced spray-dried sour cherry Marasca juice powder, $m_{\mathrm{d}}$ is dry matter content $(\mathrm{g})$ of juice in the slurry and $m_{\mathrm{c}}$ is the mass $(\mathrm{g})$ of the carrier in the slurry.

\section{Moisture content}

Moisture content (\%) of the sour cherry Marasca powders was calculated as the difference in the mass before and after drying in an oven at $105^{\circ} \mathrm{C}$ (FN 500; Nüve, Ankara, Turkey) until the constant mass was obtained (13). 


\section{Hygroscopicity}

Hygroscopicity of powders was analysed according to Tonon et al. (14). Duplicates of $1 \mathrm{~g}$ of each sample were placed in open Petri dishes in a desiccator containing saturated $\mathrm{NaCl}$ solution $(\mathrm{RH}=75.3 \%)$ and stored for one week at room temperature. Hygroscopicity was determined by measuring the mass of water adsorbed by the sample, and was expressed in $g$ of adsorbed water per 100 $\mathrm{g}$ of powder using the following equation:

$$
\text { Hygroscopicity }=\left(\frac{m_{7}-m_{0}}{m_{0}}\right) \cdot 100
$$

where $m_{7}$ is the mass $(\mathrm{g})$ of the powder after 7 days of storage and $m_{0}$ is the mass (g) of the powder before storage.

\section{Solubility}

Solubility was determined according to the method described by Anderson et al. (15), with some modifications. The mass of $1 \mathrm{~g}$ of powder was placed in a glass test tube with $10 \mathrm{~mL}$ of distilled water and stirred vigorously at vortex vibrator for $1 \mathrm{~min}$, termostated in a water bath (B-490; Büchi, Flawil, Switzerland) at $37{ }^{\circ} \mathrm{C}$ for $30 \mathrm{~min}$ and centrifuged at 5500 $\times \mathrm{g}$ for $20 \mathrm{~min}$ (Rotafix 32; Hettich, Tuttlingen, Germany). Later on, the obtained supernatant was collected and dried in a laboratory oven at $105{ }^{\circ} \mathrm{C}$ (FN 500; Nüve) until constant mass was obtained. Solubility was calculated according to the following equation:

$$
\text { Solubility }=\frac{m_{\mathrm{s}}}{m_{\mathrm{p}}} \cdot 100
$$

where $m_{\mathrm{s}}$ is the mass $(\mathrm{g})$ obtained by drying of the supernatant and $m_{\mathrm{p}}$ is the mass (g) of the powder taken into analysis.

\section{Bulk density}

Bulk density $(\mathrm{g} / \mathrm{mL})$ was determined by adding $2 \mathrm{~g}$ of sour cherry Marasca powder into an empty 10-mL graduated cylinder and holding the cylinder on a vortex vibrator for $1 \mathrm{~min}$. The ratio of the powder mass and the volume occupied in the cylinder determines the bulk density value (16).

\section{Experimental design and statistical analysis}

The experimental design and statistical analysis were done using STATISTICA v. 10 Experimental design (DOE) software (StatSoft Inc., Tulsa, OK, USA). A full factorial design comprising nine experimental trials for each carrier material used was chosen to evaluate the combined effect of two factors, carrier mass per volume ratio and drying temperature, termed $X_{1}$ and $X_{2}$, respectively (Table 1 ), giving in total 27 experimental runs. Experiments were performed in duplicate, starting with the lowest carrier mass per volume ratio and the lowest temperature. The operating variables were considered at three levels, namely low $(-1)$, central (0) and high (1). The values of carrier mass per volume ratio were set at $20(-1), 30(0)$ and $40 \%$ (1) and of temperature at $150(-1), 175(0)$ and $200{ }^{\circ} \mathrm{C}(1)$. Repetition experiments were carried out immediately after the corresponding original experiments designed by the program. The responses obtained from the experimental design were product yield (\%), moisture content $(\%)$, hygroscopicity (g/100 g), solubility (\%) and bulk density $(\mathrm{g} / \mathrm{L})$.
The design matrix for the experiment and the regression model for each response were calculated as follows (17):

$$
\mathrm{Y}=\beta_{0}+\sum \beta_{\mathrm{i}} \mathrm{X}_{\mathrm{i}}+\sum \beta_{\mathrm{ii}} \mathrm{X}_{\mathrm{i}}^{2}+\sum \beta_{\mathrm{ij}} \mathrm{X}_{\mathrm{i}} \mathrm{X}_{\mathrm{j}}
$$

where $Y$ is predicted response, $\beta_{0}$ is the fixed response, $\beta_{\mathrm{i}}$, $\beta_{\mathrm{ii}}$ and $\beta_{\mathrm{ij}}$ are the linear, quadratic and interaction coefficients, and $X_{i}$ and $X_{j}$ are independent factors, respectively.

Analysis of variance (ANOVA) was carried out to determine any significant differences $(p<0.5)$ among the applied treatments. The model was fitted by multiple linear regressions (MLR). The validity of the quadratic empirical model was tested using the analysis of variance (ANOVA). The confidence level used was $95 \%$.

For optimization purposes a prediction and profiling tool was used. Preferences were set for each response as follows: for product yield, solubility and bulk density preference was high (1.0), while for moisture content and hygroscopicity it was low (0.0). Factors were set at optimum value and were observed at 20 steps for more precise optimization.

\section{Results and Discussion}

Fruit juices are one of the most demanding materials for spray drying because of the high content of low-molecular-mass sugars and organic acids. Therefore, it is necessary to optimize the spray drying process in order to obtain the product with good physical and chemical properties, rehydration capacity and with characteristic sensory attributes. The use of drying aids, specifically the carrier materials, is mandatory as they prevent stickiness during the process and also may act as a protection of heat-sensitive compounds because of their role as microencapsulating agents (18).

In sour cherry Marasca juice powders produced according to the experimental design, the following physical and chemical parameters were determined and observed for the optimization: product yield, moisture content, hygroscopicity, solubility and bulk density (Table 1).

Product yield of powders containing MD 4-7 DE ranged from 27.7 to $59.1 \%$, of powders containing MD 13-17 DE from 6.0 to $60.4 \%$ and of powders containing GA from 34.1 to $54.3 \%$. According to the previous report by Bhandari et al. (19) the criterion for successful drying is product yield higher than $50 \%$. Almost all experimental drying conditions with MD 4-7 DE resulted in powders with product yield over $50 \%$, while with MD 13-17 DE product yield was over $50 \%$ only when using powders with higher carrier mass per volume ratio (30 and $40 \%$ ) dried at higher temperatures $\left(175\right.$ and $\left.200{ }^{\circ} \mathrm{C}\right)$. On the other hand, GA powders had yield higher than $50 \%$ only at the lowest carrier addition (20\%).

Losses during spray drying can occur as the result of different factors: residue on the dryer walls, fine particle loss through the outlet air filter and losses due to hand manipulation with powder (20).

Analysis of variance (ANOVA) results for carrier mass per volume ratio and temperature effect on the observed physical and chemical parameters are shown in 
Table 1. Results of physicochemical parameters of sour cherry Marasca juice powder produced with the addition of 20, 30 and $40 \%$ of maltodextrin (MD) with 4-7 and 13-17 dextrose equivalent (DE) and gum arabic (GA) at different drying temperatures

\begin{tabular}{|c|c|c|c|c|c|c|c|}
\hline Carrier & $\left(\frac{m \text { (carrier) }}{V \text { (juice) })}\right) / \%$ & $\frac{\text { Temperature }}{{ }^{\circ} \mathrm{C}}$ & $\frac{\text { Product yield }}{\%}$ & $\frac{\text { Moisture content }}{\%}$ & $\frac{\text { Hygroscopicity }}{\mathrm{g} / 100 \mathrm{~g}}$ & $\frac{\text { Solubility }}{\%}$ & $\frac{\text { Bulk density }}{\mathrm{g} / \mathrm{mL}}$ \\
\hline \multirow{9}{*}{ MD 4-7 DE } & \multirow{3}{*}{20} & 150 & $50.8 \pm 0.5$ & $2.3 \pm 0.1$ & $19.8 \pm 0.4$ & $95.0 \pm 0.9$ & $0.25 \pm 0.00$ \\
\hline & & 175 & $53.0 \pm 1.0$ & $1.81 \pm 0.08$ & $21.1 \pm 0.4$ & $81.8 \pm 0.4$ & $0.28 \pm 0.01$ \\
\hline & & 200 & $27.7 \pm 0.8$ & $1.36 \pm 0.06$ & $22.9 \pm 0.7$ & $89.5 \pm 1.5$ & $0.48 \pm 0.01$ \\
\hline & \multirow{3}{*}{30} & 150 & $56.0 \pm 0.7$ & $3.60 \pm 0.06$ & $26.3 \pm 0.9$ & $94.9 \pm 0.9$ & $0.30 \pm 0.01$ \\
\hline & & 175 & $50.9 \pm 1.2$ & $2.27 \pm 0.08$ & $19.5 \pm 0.7$ & $93.3 \pm 0.6$ & $0.28 \pm 0.01$ \\
\hline & & 200 & $55.8 \pm 0.8$ & $1.39 \pm 0.04$ & $19.6 \pm 0.5$ & $96.0 \pm 0.2$ & $0.28 \pm 0.01$ \\
\hline & \multirow{3}{*}{40} & 150 & $43.1 \pm 0.4$ & $3.23 \pm 0.01$ & $22.1 \pm 0.5$ & $85.2 \pm 0.5$ & $0.34 \pm 0.01$ \\
\hline & & 175 & $59.1 \pm 0.2$ & $2.49 \pm 0.04$ & $20.9 \pm 0.2$ & $86.5 \pm 0.4$ & $0.40 \pm 0.00$ \\
\hline & & 200 & $58.6 \pm 0.5$ & $1.87 \pm 0.04$ & $18.3 \pm 0.4$ & $96.1 \pm 0.2$ & $0.23 \pm 0.00$ \\
\hline \multirow{9}{*}{ MD 13-17 DE } & \multirow{3}{*}{20} & 150 & $19.4 \pm 0.8$ & $2.23 \pm 0.06$ & $30.8 \pm 0.7$ & $95.8 \pm 0.3$ & $0.36 \pm 0.00$ \\
\hline & & 175 & $12.1 \pm 0.5$ & $7.69 \pm 0.05$ & $39.0 \pm 1.0$ & $91.1 \pm 0.4$ & $0.33 \pm 0.01$ \\
\hline & & 200 & $6.0 \pm 0.5$ & $6.41 \pm 0.06$ & $39.6 \pm 0.4$ & $90.5 \pm 0.3$ & $0.34 \pm 0.01$ \\
\hline & \multirow{3}{*}{30} & 150 & $31.1 \pm 0.6$ & $3.01 \pm 0.04$ & $28.4 \pm 0.6$ & $97.8 \pm 0.8$ & $0.29 \pm 0.01$ \\
\hline & & 175 & $55.7 \pm 0.8$ & $1.53 \pm 0.05$ & $21.9 \pm 0.5$ & $97.4 \pm 0.4$ & $0.28 \pm 0.00$ \\
\hline & & 200 & $51.1 \pm 1.1$ & $1.76 \pm 0.06$ & $36.8 \pm 0.5$ & $95.2 \pm 0.3$ & $0.28 \pm 0.01$ \\
\hline & \multirow{3}{*}{40} & 150 & $46.8 \pm 0.6$ & $2.59 \pm 0.04$ & $22.9 \pm 0.7$ & $96.0 \pm 1.0$ & $0.32 \pm 0.00$ \\
\hline & & 175 & $59.5 \pm 0.8$ & $1.55 \pm 0.04$ & $23.2 \pm 0.7$ & $97.7 \pm 0.8$ & $0.25 \pm 0.01$ \\
\hline & & 200 & $60.4 \pm 1.4$ & $1.41 \pm 0.04$ & $26.0 \pm 0.4$ & $81.6 \pm 2.9$ & $0.32 \pm 0.01$ \\
\hline \multirow{9}{*}{ GA } & \multirow{3}{*}{20} & 150 & $54.3 \pm 0.6$ & $5.71 \pm 0.05$ & $23.1 \pm 0.1$ & $88.2 \pm 0.8$ & $0.28 \pm 0.01$ \\
\hline & & 175 & $51.6 \pm 0.6$ & $3.70 \pm 0.08$ & $32.5 \pm 0.4$ & $88.2 \pm 0.6$ & $0.26 \pm 0.01$ \\
\hline & & 200 & $52.0 \pm 0.3$ & $3.26 \pm 0.06$ & $34.2 \pm 1.0$ & $88.4 \pm 0.7$ & $0.24 \pm 0.01$ \\
\hline & \multirow{3}{*}{30} & 150 & $39.6 \pm 0.8$ & $5.12 \pm 0.07$ & $32.0 \pm 0.2$ & $88.2 \pm 0.7$ & $0.34 \pm 0.00$ \\
\hline & & 175 & $47.8 \pm 0.6$ & $4.31 \pm 0.09$ & $33.1 \pm 0.7$ & $86.2 \pm 0.9$ & $0.35 \pm 0.01$ \\
\hline & & 200 & $45.1 \pm 0.7$ & $3.35 \pm 0.06$ & $29.8 \pm 0.4$ & $89.0 \pm 0.9$ & $0.30 \pm 0.00$ \\
\hline & \multirow{3}{*}{40} & 150 & $46.0 \pm 0.8$ & $5.12 \pm 0.05$ & $23.0 \pm 1.0$ & $81.6 \pm 0.6$ & $0.45 \pm 0.03$ \\
\hline & & 175 & $49.8 \pm 0.6$ & $3.64 \pm 0.08$ & $29.0 \pm 0.7$ & $81.1 \pm 0.2$ & $0.39 \pm 0.01$ \\
\hline & & 200 & $34.1 \pm 0.2$ & $3.82 \pm 0.06$ & $20.8 \pm 0.5$ & $85.9 \pm 0.9$ & $0.28 \pm 0.00$ \\
\hline
\end{tabular}

Results are expressed as mean value \pm standard deviation $(N=4)$

Table 2. Both carrier mass per volume ratio and temperature, as well as combined effect of these two factors had significant influence on product yield of powders with all three carriers.

With maltodextrin carriers, regardless of dextrose equivalent, the highest carrier mass per volume ratio (40 $\%)$ and higher temperatures $\left(175\right.$ and $\left.200{ }^{\circ} \mathrm{C}\right)$ resulted in the highest product yield. With $20 \%$ MD 13-17 DE, the stickiness problem occurred, so resulting yields were very low (6.0-19.4\%), decreasing with the increase in drying temperature. The cause of the stickiness during drying is the presence of low-molecular-mass sugars, namely sucrose, glucose and fructose, which have low glass transition temperature $(19,21)$ and therefore tend to stick to the dryer walls, leading to low product yield and technical difficulties during process. Low glass transition temperature, high hygroscopicity, low melting point and high water solubility characterize juice dry matter and make them highly sticky products. These problems are solved by the addition of carrier materials, polymers and gums, which have the ability to increase the glass transition tempera- ture of juice and consequently decrease or inhibit the stickiness phenomenon (22). Carrier efficiency primarily depends on its ratio to the juice dry matter and drying temperature. According to our results, it can be concluded that the use of MD 13-17 DE demands higher carrier ratio as with $20 \%$ carrier addition to the juice with $15 \%$ dry matter, the stickiness problem occurred, being more expressed with the rise of the drying temperature.

On the other hand, with gum arabic, the highest product yields were obtained with the lowest carrier ratio, regardless of the drying temperature. Vardin and Yasar (11) optimized the spray drying process of pomegranate juice and reported the highest yield at juice to MD ratio $1: 2$ and temperatures from 110 to $140{ }^{\circ} \mathrm{C}$ with decreasing trend at higher temperatures. Dextrose equivalent was also found to be significant as MD with lower DE gave higher yields at higher ratios and lower temperatures. In the present study, both maltodextrins gave similar yields at higher ratios and temperatures, regardless of the dextrose equivalent. Other authors showed compara- 
Table 2. Analysis of variance (ANOVA) for the effect of carrier mass per volume ratio $\left(X_{1}\right)$ and temperature $\left(X_{2}\right)$ on the observed physicochemical parameters of spray-dried sour cherry Marasca juice powder produced with the addition of maltodextrin (MD) of 4-7 and 13-17 dextrose equivalent (DE) and gum arabic (GA) at $95 \%$ confidence level

\begin{tabular}{|c|c|c|c|c|c|c|c|c|c|c|c|}
\hline \multirow{2}{*}{ Carrier } & \multirow{2}{*}{$\begin{array}{l}\text { Source of } \\
\text { variation }\end{array}$} & \multicolumn{2}{|c|}{ Product yield } & \multicolumn{2}{|c|}{ Moisture content } & \multicolumn{2}{|c|}{ Hygroscopicity } & \multicolumn{2}{|c|}{ Solubility } & \multicolumn{2}{|c|}{ Bulk density } \\
\hline & & F-ratio & $\mathrm{p}$-value & F-ratio & $\mathrm{p}$-value & F-ratio & $\mathrm{p}$-value & F-ratio & $\mathrm{p}$-value & F-ratio & $\mathrm{p}$-value \\
\hline \multirow{3}{*}{$\begin{array}{l}\text { MD 4-7 } \\
\text { DE }\end{array}$} & $\mathrm{X}_{1}$ & 371.60 & 0.00 & 203.81 & 0.00 & 9.81 & 0.01 & 122.50 & 0.00 & 75.98 & 0.00 \\
\hline & $x_{2}$ & 135.74 & 0.00 & 793.48 & 0.00 & 37.43 & 0.00 & 128.93 & 0.00 & 32.42 & 0.00 \\
\hline & $\mathrm{X}_{1} \mathrm{X}_{2}$ & 458.49 & 0.00 & 51.97 & 0.00 & 52.20 & 0.00 & 86.51 & 0.00 & 428.38 & 0.00 \\
\hline \multirow{3}{*}{$\begin{array}{l}\text { MD 13-17 } \\
\text { DE }\end{array}$} & $X_{1}$ & 4282.37 & 0.00 & 10129.56 & 0.00 & 577.60 & 0.00 & 36.45 & 0.00 & 125.74 & 0.00 \\
\hline & $X_{2}$ & 218.07 & 0.00 & 609.57 & 0.00 & 206.48 & 0.00 & 79.73 & 0.00 & 35.08 & 0.00 \\
\hline & $\mathrm{X}_{1} \mathrm{X}_{2}$ & 272.15 & 0.00 & 3550.71 & 0.00 & 100.72 & 0.00 & 33.55 & 0.00 & 17.51 & 0.00 \\
\hline \multirow{3}{*}{ GA } & $X_{1}$ & 435.30 & 0.00 & 1.49 & 0.28 & 228.00 & 0.00 & 103.59 & 0.00 & 119.83 & 0.00 \\
\hline & $X_{2}$ & 144.02 & 0.00 & 1186.55 & 0.00 & 118.75 & 0.00 & 19.92 & 0.00 & 67.78 & 0.00 \\
\hline & $X_{1} X_{2}$ & 161.94 & 0.00 & 71.71 & 0.00 & 33.73 & 0.00 & 7.23 & 0.01 & 19.93 & 0.00 \\
\hline
\end{tabular}

ble results regarding the carrier ratio, while the ones dealing with the effect of drying temperature are diverse. Peng et al. (23) researched the influence of MD 20 DE addition on the product yield of spray-dried purple sweet potato. The addition of $30 \% \mathrm{MD} 20 \mathrm{DE}$ increased product yield from 23.32 to $39.85 \%$, while further addition gave no effect. The importance of carrier use is in the formation of outer layer, the 'wall' surrounding the material and increase of glass transition temperature which results in prevention of stickiness and increase in product yield (24). For effective spray drying of concentrated blackcurrant, apricot and raspberry juices, the addition of minimally $35 \%$ of MD 6 DE was necessary (9), while Righetto and Netto (25) reported the minimum addition of $50 \%$ of MD 25 DE to acerola juice.

Fazaeli et al. (26) reported the effect of drying temperature similar to our conclusions. They observed the positive effect of temperature increase on spray-dried black mulberry juice yield, explained by more effective energy and mass transfer at elevated temperatures $(14,27)$.

Moisture content of sour cherry Marasca powders varied from $1.36-2.49 \%$ in those containing MD 4-7 DE, from $1.41-7.69 \%$ in those containing MD 13-17 DE and from $3.26-5.71 \%$ in those containing GA. This is one of the most important indicators of spray drying effectiveness and final product quality (28).

According to the ANOVA results (Table 2) both carrier mass per volume ratio and drying temperature had significant effect on moisture content of sour cherry Marasca powders produced with MD carriers, while in powders produced with GA there was no significant effect of carrier mass per volume ratio.

Generally, powders produced with MD 4-7 DE had the lowest moisture content, while those with GA had the highest. The exception are powders produced with $20 \%$ of MD 13-17 DE at 175 and $200{ }^{\circ} \mathrm{C}$, which had high moisture residue due to the stickiness that occurred during the process. It can also be observed that increase in MD 13-17 DE carrier mass per volume ratio had evidently positive effect on moisture content decrease, which reduced the stickiness problem. These findings are in accordance with other authors' reports.
At higher drying temperatures, the resulting moisture content is lower thanks to more effective mass and heat transfer, namely intensive water evaporation (29). Fazaeli et al. (26) also reported the reduction of moisture content in black mulberry juice powder with temperature increase as well as with the increase in carrier concentration. Rodríguez-Hernández et al. (30) observed lower moisture content in Opuntia powders produced with maltodextrins with higher dextrose equivalent, while Fazaeli et al. (26) and Goula and Adamopoulos (27) reported adverse findings for sweet potato and orange juice powders. These authors explained their findings with the structure of maltodextrin with high dextrose equivalent characterized by more short chains and hydrophilic groups which consequently adsorb more water molecules. The results of our research showed that there was no significant difference in the moisture content of powders produced with MD 4-7 DE and MD 13-17 DE at higher mass per volume ratios (30 and $40 \%$ ), but results with the addition of $20 \% \mathrm{MD}$ are in accordance with the above mentioned studies.

Hygroscopicity of sour cherry Marasca juice powders containing MD 4-7 DE ranged from 18.3 to $26.3 \mathrm{~g} / 100 \mathrm{~g}$, in powders containing MD 13-17 DE from 21.9 to 39.6 $\mathrm{g} / 100 \mathrm{~g}$ and in powders containing GA from 20.8 to 34.2 $\mathrm{g} / 100 \mathrm{~g}$. Hygroscopicity is a parameter that describes the flowability of powders very well, as more hygroscopic powders are less free flowing due to more adsorbed moisture (31). Both hygroscopicity and flowability depend on the glass transition temperature. The higher the glass transition temperature, the lower the hygroscopicity and the higher the flowability (32).

According to the ANOVA results, all observed parameters individually, as well as combined, had a significant influence on hygroscopicity of powders with all three carriers used. Powders produced with the MD 4-7 DE had the lowest hygroscopicity, followed by the MD 13-17 DE and the GA with the highest hygroscopicity. Vardin and Yasar (11) also reported higher hygroscopicity of powders produced with maltodextrin with higher dextrose equivalent $(18 \mathrm{DE})$ in comparison with $7 \mathrm{DE}$. Low-molecular-mass maltodextrins are more susceptible to water adsorption due to more hydrophilic groups (33). 
Higher mass per volume ratio of carrier material and higher drying temperatures had positive effect on hygroscopicity decrease, which is in accordance with previous findings. Moreira et al. (34) reported the decrease in hygroscopicity of acerola powders with an increase in temperature from 170 to $200{ }^{\circ} \mathrm{C}$, explained by the lower moisture content. Tonon et al. (14) observed the influence of higher maltodextrin concentration on the decrease of hygroscopicity of acai powders.

The solubility of powders ranged from 81.8 to $96.1 \%$ in those containing MD 4-7 DE, from 81.6 to $97.8 \%$ in those with MD 13-17 DE and from 81.1 to $89.0 \%$ in powders containing GA. It can be observed that regardless of the drying conditions, the powders with GA had significantly lower solubility than the ones with MD, which is related to the different structure and properties of gums and maltodextrins, although the GA is considered as the gum with high water solubility.

Both carrier mass per volume ratio and temperature significantly influenced the water solubility of powders with all carriers used (Table 2). General observation is that powders containing $30 \%$ carrier mass per volume ratio have better solubility. Fazaeli et al. (26) also observed the positive effect of higher maltodextrin mass per volume ratio on the solubility of powders due to the high maltodextrin solubility in water. Contrary to these findings, Selvamuthukumaran and Khanum (35) reported the negative effect of higher maltodextrin mass per volume ratios on the solubility of sea buckthorn powder, caused by the higher amount of insoluble residue and more lumps formed during the dissolution. MD 13-17 DE carrier showed opposite behaviour under the influence of different temperatures compared to MD 4-7 DE and GA; its solubility decreased at higher drying temperatures. Quek et al. (29) reported the negative effect of temperature on the solubility of watermelon powders, similar to the behaviour of powders containing MD 13-17 DE in our study, while temperature increase favoured the solubility of black mulberry and pomegranate powder $(11,26)$.

Bulk density of powders ranged from 0.23 to $0.48 \mathrm{~g} /$ $\mathrm{mL}$ in powders containing MD 4-7 DE, from 0.25 to 0.36 $\mathrm{g} / \mathrm{mL}$ in powders containing MD 13-17 DE and from 0.24 to $0.45 \mathrm{~g} / \mathrm{mL}$ in powders containing GA. Compared to the sour cherry Marasca juice powders, the bulk density of other powder juices was generally higher (in $\mathrm{g} / \mathrm{mL}$ ): pomegranate powder 0.579-0.687 (11), lime powder 0.410.69 (36), except for pitaya powder, which was lower, $0.29-0.34$ (37).

Generally, the heavier the powder is, the more easily it fills the space between the particles, resulting in higher bulk density. Therefore, the bulk density includes the particles and the space between them and can be related to the powder porosity which includes only the space between the particles (38).

All observed drying parameters had a significant influence on bulk density of sour cherry Marasca juice powders regardless of the carrier used. In powders containing maltodextrin, bulk density was higher with lower carrier mass per volume ratio, contrary to powders containing GA. Regarding the drying temperature, powders produced with MD 4-7 DE had higher bulk density when dried at higher temperatures, while powders produced with MD 13-17 DE and GA had higher bulk density at lower temperatures.

The increase in drying temperature also caused lower bulk density of black mulberry powders in the study of Fazaeli et al. (26). Particularly, at higher temperatures the water evaporation rate is faster, dried powder has more porous and fragmented structure, larger particles are formed and therefore the bulk density is lower. Higher temperature usually results in larger particles with more inside cavities (39). The same trend is confirmed in studies on gac fruit aril powder (2) and pomegranate powder (11). Goula and Adamopouls (40) reported the increase in bulk density of powders with higher dextrose equivalent of maltodextrin while our results show no significant difference between MD 4-7 DE and MD 13-17 DE.

Table 3 shows the equations of regression models for product yield, moisture content, hygroscopicity, solubility and bulk density of sour cherry Marasca juice powders produced with MD 4-7 DE, MD 13-17 DE and GA. In these models, studied spray drying parameters (carrier mass per volume ratio and temperature) are combined in linear, quadratic and interaction coefficients, enabling the prediction of response variable values for any desired carrier mass per volume ratio and drying temperature. The adequacy of the model was checked by calculating the coefficient of determination, $\mathrm{R}^{2}$, which is the proportion of variation in the response attributed to the model rather than to random error. It has been suggested that a good-fitting model should have $\mathrm{R}^{2}$ no less than $80 \%$. As it can be observed, all models had the $\mathrm{R}^{2}$ higher than 0.9 , which implicates the adequacy of the models to predict the physicochemical properties of powders. While $\mathrm{R}^{2}$ indicates how much of the observed variability in the data was accounted for by the model, $R_{\text {adj }}^{2}$ modifies $R^{2}$ by taking into account the number of covariates or predictors in the model. An $\mathrm{R}_{\text {adj }}^{2}$ close to the $\mathrm{R}^{2}$ values insures a satisfactory adjustment of the quadratic models to the experimental data. As it can be observed, all $\mathrm{R}_{\text {adj }}^{2}$ values were close to the $R^{2}$, implying that the models explained the observed powder properties very well. Results of the optimization of spray drying with each carrier are shown in Table 4. Optimization was carried out using the response surface methodology in order to obtain the drying parameters resulting in the powder with high production yield, low moisture content and hygroscopicity, high solubility and high bulk density. Optimal drying conditions are almost similar for powders with MD 4-7 DE and GA, the highest drying temperature of $200{ }^{\circ} \mathrm{C}$, and about $30 \%$ of carrier, twice higher than juice dry matter content, namely $27 \%$ of MD 4-7 DE and $31 \%$ of GA. For powders produced with MD 13-17 DE, required carrier addition is higher, $40 \%$, while drying temperature is lower, $150{ }^{\circ} \mathrm{C}$. These differences are the result of the influence of maltodextrin with higher dextrose equivalent on the powder stickiness at higher temperatures when applied in lower mass per volume ratio.

The optimal conditions for spray drying depend primarily on the material that is to be dried. Therefore, Vardin and Yasar (11) reported the optimal temperature for pomegranate juice drying in the range from 125 to $145^{\circ} \mathrm{C}$, optimal juice dry matter to carrier ratio of $0.6-0.8$ and car- 
Table 3. Regression models for the physicochemical parameters of spray-dried sour cherry Marasca juice powder produced with the addition of maltodextrin (MD) with 4-7 and 13-17 dextrose equivalent (DE) and gum arabic (GA), and corresponding values of coefficient of determination $\left(R^{2}\right)$ and adjusted coefficient of determination $\left(R_{\text {adj }}^{2}\right)$

\begin{tabular}{|c|c|c|c|c|}
\hline Carrier & Response & Model & $\mathrm{R}^{2}$ & $\mathrm{R}_{\text {adj }}^{2}$ \\
\hline \multirow{5}{*}{$\begin{array}{l}\text { MD } \\
4-7 \\
\mathrm{DE}\end{array}$} & Product yield & $-6814.82+466.84 \mathrm{X}_{1}-7.66 \mathrm{X}_{1}^{2}+80.72 \mathrm{X}_{2}-0.24 \mathrm{X}_{2}^{2}-5.45 \mathrm{X}_{1} \mathrm{X}_{2}+0.02 \mathrm{X}_{1} \mathrm{X}_{2}^{2}+0.09 \mathrm{X}_{1}^{2} \mathrm{X}_{2}$ & 0.997 & 0.994 \\
\hline & Moisture content & $-102.45+8.012 X_{1}-0.13 X_{1}^{2}+1.011 X_{2}-0.002 X_{2}^{2}-0.077 X_{1} X_{2}+0.001 X_{1}^{2} X_{2}$ & 0.995 & 0.992 \\
\hline & Hygroscopicity & $-1571.24+120.16 \mathrm{X}_{1}-2.02 \mathrm{X}_{1}^{2}+17.14 \mathrm{X}_{2}-0.05 \mathrm{X}_{2}^{2}-1.3 \mathrm{X}_{1} \mathrm{X}_{2}+0.02 \mathrm{X}_{1}^{2} \mathrm{X}_{2}$ & 0.971 & 0.946 \\
\hline & Solubility & $2875.015-160.806 \mathrm{X}_{1}+2.381 \mathrm{X}_{1}^{2}-32.637 \mathrm{X}_{2}+0.093 \mathrm{X}_{2}^{2}+1.906 \mathrm{X}_{1} \mathrm{X}_{2}-0.005 \mathrm{X}_{1} \mathrm{X}_{2}^{2}-0.029 \mathrm{X}_{1}^{2} \mathrm{X}_{2}$ & 0.990 & 0.980 \\
\hline & Bulk density & $\begin{array}{l}2.53375+0.317177 X_{1}-0.012493 X_{1}^{2}-0.046082 X_{2}+0.000201 X_{2}^{2}-0.002655 X_{1} X_{2}+0.000004 X_{1} X_{2}^{2}+ \\
0.000133 X_{1}^{2} X_{2}\end{array}$ & 0.995 & 0.991 \\
\hline \multirow{5}{*}{$\begin{array}{l}\text { MD } \\
13-17 \\
\text { DE }\end{array}$} & Product yield & $5509.751-397.496 \mathrm{X}_{1}+6.32 \mathrm{X}_{1}^{2}-61.203 \mathrm{X}_{2}+0.163 \mathrm{X}_{2}^{2}+4.441 \mathrm{X}_{1} \mathrm{X}_{2}-0.012 \mathrm{X}_{1} \mathrm{X}_{2}^{2}-0.071 \mathrm{X}_{1}^{2} \mathrm{X}_{2}$ & 0.999 & 0.998 \\
\hline & Moisture content & $-1333.47+82.13 \mathrm{X}_{1}-1.20 \mathrm{X}_{1}^{2}+15.05 \mathrm{X}_{2}-0.04 \mathrm{X}_{2}^{2}-0.93 \mathrm{X}_{1} \mathrm{X}_{2}+0.01 \mathrm{X}_{1}^{2} \mathrm{X}_{2}$ & 0.999 & 0.999 \\
\hline & Hygroscopicity & $-4945.96+351.6 X_{1}-5.65 X_{1}^{2}+58.09 X_{2}-0.17 X_{2}^{2}-4.11 X_{1} X_{2}+0.01 X_{1} X_{2}^{2}+0.07 X_{1}^{2} X_{2}$ & 0.995 & 0.991 \\
\hline & Solubility & $-88.88+34.8542 X_{1}-0.9953 X_{1}^{2}+2.7954 X_{2}-0.0111 X_{2}^{2}-0.4522 X_{1} X_{2}+0.0015 X_{1} X_{2}^{2}+0.0125 X_{1}^{2} X_{2}$ & 0.976 & 0.955 \\
\hline & Bulk density & $\begin{array}{l}16.7336-1.20783 X_{1}+0.02196 X_{1}^{2}-0.18481 X_{2}+0.00053 X_{2}^{2}+0.01367 X_{1} X_{2}-0.00004 X_{1} X_{2}^{2}- \\
0.00025 X_{1}^{2} X_{2}\end{array}$ & 0.978 & 0.958 \\
\hline \multirow{5}{*}{ GA } & Product yield & 1583.251-95.192 $\mathrm{X}_{1}+1.151 \mathrm{X}_{1}^{2}-15.357 \mathrm{X}_{2}+0.039 \mathrm{X}_{2}^{2}+0.926 \mathrm{X}_{1} \mathrm{X}_{2}-0.002 \mathrm{X}_{1} \mathrm{X}_{2}^{2}-0.01 \mathrm{X}_{1}^{2} \mathrm{X}_{2}$ & 0.995 & 0.991 \\
\hline & Moisture content & $395.26-25.792 X_{1}+0.4283 X_{1}^{2}-4.4448 X_{2}+0.0124 X_{2}^{2}+0.2968 X_{1} X_{2}-0.0008 X_{1} X_{2}^{2}-0.0049 X_{1}^{2} X_{2}$ & 0.997 & 0.994 \\
\hline & Hygroscopicity & $-1574.97+106.22 \mathrm{X}_{1}-1.87 \mathrm{X}_{1}^{2}+16.65 \mathrm{X}_{2}-0.04 \mathrm{X}_{2}^{2}-1.11 \mathrm{X}_{1} \mathrm{X}_{2}+0.02 \mathrm{X}_{1}^{2} \mathrm{X}_{2}$ & 0.991 & 0.984 \\
\hline & Solubility & $-468.38+39.269 X_{1}-0.567 X_{1}^{2}+6.149 X_{2}-0.017 X_{2}^{2}-0.429 X_{1} X_{2}+0.001 X_{1} X_{2}^{2}+0.007 X_{1}^{2} X_{2}$ & 0.968 & 0.940 \\
\hline & Bulk density & $\begin{array}{l}\text { 9.9057-0.70614 } X_{1}+0.011482 X_{1}^{2}-0.104354 X_{2}+0.000271 X_{2}^{2}+0.00759 X_{1} X_{2}-0.00002 X_{1} X_{2}^{2}- \\
0.00012 X_{1}^{2} X_{2}\end{array}$ & 0.981 & 0.963 \\
\hline
\end{tabular}

Table 4. Predicted and experimental values of physicochemical parameters of spray-dried sour cherry Marasca juice powder produced with the addition of maltodextrin (MD) with 4-7 and 13-17 dextrose equivalent (DE) and gum arabic (GA) at optimal conditions for each carrier used

\begin{tabular}{|c|c|c|c|c|c|c|c|c|}
\hline & \multicolumn{2}{|c|}{$\begin{array}{l}\text { Optimal drying } \\
\text { conditions }\end{array}$} & & \multirow{2}{*}{$\begin{array}{c}\begin{array}{c}\text { Product } \\
\text { yield }\end{array} \\
\%\end{array}$} & \multirow{3}{*}{$\begin{array}{c}\begin{array}{c}\text { Moisture } \\
\text { content }\end{array} \\
\%\end{array}$} & \multirow{3}{*}{$\frac{\text { Hygroscopicity }}{\mathrm{g} / 100 \mathrm{~g}}$} & \multirow{3}{*}{$\frac{\text { Solubility }}{\%}$} & \multirow{3}{*}{$\frac{\text { Bulk density }}{\mathrm{g} / \mathrm{mL}}$} \\
\hline & $(m$ (carrier) $)$ & & & & & & & \\
\hline & $\overline{V \text { (juice) }})^{1 \%}$ & $t /{ }^{\circ} \mathrm{C}$ & & $\%$ & & & & \\
\hline \multirow{2}{*}{$\begin{array}{l}\text { MD 4-7 } \\
\text { DE }\end{array}$} & \multirow{2}{*}{27} & \multirow{2}{*}{200} & Predicted value & 50.06 & 1.33 & 20.39 & 94.72 & 0.32 \\
\hline & & & Experimental value & 51.17 & 1.30 & 20.04 & 95.08 & 0.32 \\
\hline \multirow{2}{*}{$\begin{array}{l}\text { MD 13-17 } \\
\text { DE }\end{array}$} & \multirow{2}{*}{40} & \multirow{2}{*}{150} & Predicted value & 46.79 & 2.59 & 22.94 & 96.04 & 0.32 \\
\hline & & & Experimental value & 47.23 & 2.75 & 22.16 & 96.97 & 0.32 \\
\hline \multirow{2}{*}{ GA } & \multirow{2}{*}{31} & \multirow{2}{*}{200} & Predicted value & 44.18 & 3.37 & 29.06 & 88.88 & 0.30 \\
\hline & & & Experimental value & 44.65 & 3.53 & 28.84 & 89.01 & 0.30 \\
\hline
\end{tabular}

rier MD 7 DE rather than MD 18 DE. Krishnaiah et al. (41) used temperature of $95^{\circ} \mathrm{C}$ and maltodextrin to dry matter ratio of 1.5 for drying of the noni extract, while Selvamuthukumaran and Khanum (35) applied temperature of $162.5^{\circ} \mathrm{C}$ and $25 \%$ carrier for optimized spray drying process of sea buckthorn juice. Having in mind the differences among the dried materials, all these results are comparable and in accordance with the findings in our study. On the other hand, Karaca et al. (42) researched similar material, sour cherry concentrate, and reported the optimal spray drying conditions to be $150{ }^{\circ} \mathrm{C}, 25 \%$ sour cherry content with carrier MD $12 \mathrm{DE}$, resulting in yield higher than $85 \%$. The temperature effect findings are in accordance with our conclusions on higher dextrose equivalent maltodextrins but resulting yields are higher than in our study. These differences may derive from the higher carrier mass per volume ratio applied in the reported study as well as from the different spray dryers used, as construction differences, especially those regarding the outlet temperature control and outlet filters, influence the yield losses to a high extent. At defined optimal conditions, physicochemical parameters were predicted by the model and confirmed in experimental trials. Experimental results support the adequacy of the models for prediction of powder properties. It can be observed that powders produced with MD 4-7 DE had the highest product yield, the lowest moisture content and hygroscopicity, and the highest bulk density. On the other hand, powders containing GA had the lowest yield and solubility and the highest moisture content and hygroscopicity. Taking into account the above mentioned, it can be concluded that the MD 4-7 DE is the most suitable carrier for production of the spray-dried sour cherry juice Marasca powder with the best physicochemical properties. 


\section{Conclusions}

This study confirmed that carrier material, its mass per volume ratio and drying temperature significantly affect the physical and chemical properties of spray-dried sour cherry Marasca juice powder. Generally, higher maltodextrin carrier amounts caused the increase in product yield, increase of both maltdextrin and gum arabic mass per volume ratio up to $30 \%$ positively affected the powder solubility, while bulk density was highest at $40 \%$ carrier addition. High carrier mass per volume ratio decreased the moisture content and hygroscopicity of powders. Higher drying temperature decreased their moisture content and bulk density. Maltodextrin with low dextrose equivalent showed better stickiness reduction properties than the one with higher dextrose equivalent, while gum arabic, although with good stickiness reduction properties, produced powders with lower yield and solubility, and with high moisture content and hygroscopicity.

According to the obtained results, it can be concluded that the sour cherry Marasca juice powder with the optimal physicochemical properties is produced with the addition of $27 \%$ of maltodextrin with dextrose equivalent of 4-7 at drying temperature of $200{ }^{\circ} \mathrm{C}$. Further studies have to be done regarding the influence of the abovementioned parameters on the phenolic content of the obtained powders in order to design the final product.

\section{Acknowledgements}

This study was part of the project co-financed by the European Union from the Science and Innovation Investment Fund, Component IIIC, Operational Programme of Regional Competitiveness: Marasca Sour Cherry (Prunus cerasus var. Marasca) as an Ingredient for Functional Food (IPA 2007/HR/16IPO/001-040302).

\section{References}

1. Chou SK, Chua KJ. New hybrid drying technologies for heat sensitive foodstuffs. Trends Food Sci Tech. 2001;12:359-69. http://dx.doi.org/10.1016/S0924-2244(01)0012-9

2. Kha TC, Nguyen MH, Roach PD. Effects of spray drying conditions on the physicochemical and antioxidant properties of the gac (Momordica cochinchinensis) fruit aril powder. J Food Eng. 2010;98:385-92.

http://dx.doi.org/10.1016/j.jfoodeng.2010.01.016

3. Verma A, Singh SV. Spray drying of fruit and vegetable juices - a review. Crit Rev Food Sci Nutr. 2015;55:701-19. http://dx.doi.org/10.1080/10408398.2012.672939

4. Masters K. Spray drying handbook. New York, NY, USA: John Wiley and Sons, Inc.; 1991.

5. Pedisić S, Levaj B, Dragović-Uzelac V, Kos K. Physicochemical composition, phenolic content and antioxidant activity of sour cherry cv. Marasca during ripening. Agric Conspec Sci. 2007;72:295-300.

6. Elez Garofulić I, Režek Jambrak A, Milošević S, DragovićUzelac V, Zorić Z, Herceg Z. The effect of gas phase plasma treatment on the anthocyanin and phenolic acid content of sour cherry Marasca (Prunus cerasus var. Marasca) juice. LWT - Food Sci Technol. 2015;62:894-900. http://dx.doi.org/10.1016/j.lwt.2014.08.036

7. Zorić Z, Dragović-Uzelac V, Pedisić S, Kurtanjek Ž, Elez Garofulić I. Kinetics of the degradation of anthocyanins, phenolic acids and flavonols during heat treatments of freeze-dried sour cherry Marasca paste. Food Technol Biotechnol. 2014;52:101-8.

8. Elez Garofulić I, Dragović-Uzelac V, Režek Jambrak A, Jukić $M$. The effect of microwave assisted extraction on the isolation of anthocyanins and phenolic acids from sour cherry Marasca (Prunus cerasus var. Marasca). J Food Eng. 2013; 117:437-42. http://dx.doi.org/10.1016/j.jfoodeng.2012.12.043

9. Bhandari BR, Senoussi A, Dumoulin ED, Lebert A. Spray drying of concentrated fruit juices. Drying Technol. 1993;11: 1081-92. http://dx.doi.org/10.1080/07373939308916884

10. Phisut N. Spray drying technique of fruit juice powder: some factors influencing the properties of product. Int Food Res J. 2012;19:1297-306.

11. Vardin H, Yasar M. Optimisation of pomegranate (Punica granatum L.) juice spray-drying as affected by temperature and maltodextrin content. Int J Food Sci Technol. 2012;47: $167-76$. http://dx.doi.org/10.1111/j.1365-2621.2011.02823.x

12. Solval KM, Sundararajan S, Alfaro L, Sathivel S. Development of cantaloupe (Cucumis melo) juice powders using spray drying technology. LWT - Food Science Technol. 2012;46:287-93.

http://dx.doi.org/10.1016/j.lwt.2011.09.017

13. AOAC Official Method 920.151. Solids (total) in fruits and fruit products. Rockville, MD, USA: AOAC International; 2000.

14. Tonon RV, Brabet C, Hubinger MD. Influence of process conditions on the physicochemical properties of acąi (Euterpe oleraceae Mart.) powder produced by spray drying. J Food Eng. 2008;88:411-8. http://dx.doi.org/10.1016/j.jfoodeng.2008.02.029

15. Anderson RA, Conway HF, Pfeifer VF, Griffin JR. Roll and extrusion-cooking of grain sorghum grits. Cereal Sci Today. 1969;14:372-6.

16. Beristain CI, Garcia HS, Vernon-Carter EJ. Spray-dried encapsulation of cardamom (Elettaria cardamomum) essential oil with Mesquite (Prosopis juliflora) gum. LWT - Food Sci Technol. 2001;34:398-401. http://dx.doi.org/10.1006/fstl.2001.0779

17. Khuri AI, Cornell JA. Response surfaces: design and analyses. Boca Raton, FL, USA: CRC Press; 1996.

18. Gharsallaoui A, Roudaut G, Voilley CO, Saurel R. Applications of spray-drying in microencapsulation of food ingredients: an overview. Food Res Int. 2007;40:1107-21. http://dx.doi.org/10.1016/j.foodres.2007.07.004

19. Bhandari BR, Datta N, Howes T. Problem associated with spray drying of sugar-rich foods. Drying Technol. 1997;15: 671-84. http://dx.doi.org/10.1080/07373939708917253

20. Fang Z, Bhandari B. Effect of spray drying and storage on the stability of bayberry polyphenols. Food Chem. 2011;129: 1139-47. http://dx.doi.org/10.1016/j.foodchem.2011.05.093

21. Jittanit W, Niti-Att S, Techanuntachikul O. Study of spray drying of pineapple juice using maltodextrin as an adjunct. Chiang Mai J Sci. 2010;37:498-506.

22. Roos YH, Karel M. Plasticizing effect of water on thermal behaviour and crytallization of amorphous food models. J Food Sci. 1991;56:38-43. http://dx.doi.org/10.1111/j.1365-2621.1991.tb07970.x

23. Peng Z, Li J, Guan Y, Zhao G. Effect of carriers on physicochemical properties, antioxidant activities and biological 
components of spray-dried purple sweet potato flours. LWT - Food Sci Technol. 2013;51:348-55. http://dx.doi.org/10.1016/j.lwt.2012.09.022

24. Ahmed M, Akter MS, Lee JC, Eun JB. Encapsulation by spray drying of bioactive components, physicochemical and morphological properties from purple sweet potato. LWT - Food Sci Technol. 2010;43:1307-12. http://dx.doi.org/10.1016/j.lwt.2010.05.014

25. Righetto AM, Netto FM. Effect of encapsulating materials on water sorption, glass transition and stability of juice from immature acerola. Int J Food Prop. 2005;8:337-46. http://dx.doi.org/10.1081/JFP-200060262

26. Fazaeli M, Emam-Djomeh Z, Kalbasi Ashtari A, Omid M. Effect of spray drying conditions and feed composition on the physical properties of black mulberry juice powder. Food Bioprod Process. 2012;90:667-75. http://dx.doi.org/10.1016/j.fbp.2012.04.006

27. Goula AM, Adamopoulos KG. A new technique for spray drying orange juice concentrate. Innov Food Sci Emerg Technol. 2010;11:342-51. http://dx.doi.org/10.1016/j.ifset.2009.12.001

28. Rattes ALR, Oliveira WP. Spray drying conditions and encapsulating composition effects on formation and properties of sodium diclofenac microparticles. Powder Technol. 2007; 171:7-14.

http://dx.doi.org/10.1016/j.powtec.2006.09.007

29. Quek SY, Chok NK, Swedlund P. The physicochemical properties of spray-dried watermelon powders. Chem Eng Process. 2007;46:386-92. http://dx.doi.org/10.1016/j.cep.2006.06.020

30. Rodríguez-Hernández GR, González-García R, Grajales-Lagunes A, Ruiz-Cabrera MA, Abud-Archila M. Spray-drying of cactus pear juice (Opuntia streptacantha): effect on the physicochemical properties of powder and reconstituted product. Drying Technol. 2005;23:955-73. http://dx.doi.org/10.1080/DRT-200054251

31. Fitzpatrick JJ. Food powder flowability. In: Onwulata C, editor. Encapsulated and powdered foods. Boca Raton, FL, USA: CRC Press; 2005. pp. 247-60. http://dx.doi.org/10.1201/9781420028300.ch10

32. De Oliveira MA, Maia GA, De Figueiredo RW, De Souza ACR, De Brito ES, De Azeredo HMC. Addition of cashew tree gum to maltodextrin-based carriers for spray drying of cashew apple juice. Int J Food Sci Technol. 2009;44:641-5. http://dx.doi.org/10.1111/j.1365-2621.2008.01888.x
33. Cai YZ,Corke H. Production and properties of spray-dried Amaranthus betacyanin pigments. J Food Sci. 2000;65:1248-52. http://dx.doi.org/10.1111/j.1365-2621.2000.tb10273.x

34. Moreira GEG, Costa MGM, de Souza ACR, de Brito ES, de Medeiros MFD, de Azeredo HMC. Physical properties of spray dried acerola pomace extract as affected by temperature and drying aids. LWT - Food Sci Technol. 2009;42:641-5. http://dx.doi.org/10.1016/j.lwt.2008.07.008

35. Selvamuthukumaran M, Khanum F. Optimization of spray drying process for developing seabuckthorn fruit juice powder using response surface methodology. J Food Sci Technol. 2014;51:3731-9. http://dx.doi.org/10.1007/s13197-012-0901-y

36. Zareifard MR, Niakousari M, Shokrollahi Z, Javadian S. A feasibility study on the drying of lime juice: the relationship between the key operating parameters of a small laboratory spray dryer and product quality. Food Bioprocess Technol. 2012;5:1896-906. http://dx.doi.org/10.1007/s11947-011-0689-1

37. Tze NL, Han CP, Yusof YA, Ling CN, Talib RA, Taip FS, Aziz MG. Physicochemical and nutritional properties of spray-dried pitaya fruit powder as natural colorant. Food Sci Biotechnol. 2012;21:675-82. http://dx.doi.org/10.1007/s10068-012-0088-z

38. Tonon RV, Brabet C, Hubinger MD. Anthocyanin stability and antioxidant activity of spray-dried açai (Euterpe oleracea Mart.) juice produced with different carrier agents. Food Res Int. 2010;43:907-14. http://dx.doi.org/10.1016/j.foodres.2009.12.013

39. Walton DE. The morphology of spray-dried particles, a qualitative view. Drying Technol. 2000;18:1943-86. http://dx.doi.org/10.1080/07373930008917822

40. Goula AM, Adamopoulos KG. Stability of lycopene during spray drying of tomato pulp. LWT - Food Sci Technol. 2005; 38:479-87. http://dx.doi.org/10.1016/j.lwt.2004.07.020

41. Krishnaiah D, Bono A, Sarbatly R, Nithyanandam R, Anisuzzaman SM. Optimisation of spray drying operating conditions of Morinda citrifolia L. fruit extract using response surface methodology. J King Saudi Univ Eng Sci. 2015;27:26-36. http://dx.doi.org/10.1016/j.jksues.2012.10.004

42. Karaca AC, Guzel O, Ak MM. Effects of processing conditions and formulation on spray drying of sour cherry juice concentrate. J Sci Food Agric. 2016;96:449-55. http://dx.doi.org/10.1002/jsfa.7110 